\title{
SEISMIC Analysis of high-rise buildings with composite metal damper
}

Ruixue Chen $^{1, a}$, Guolei Xing ${ }^{1}$

\author{
State nuclear electric power planning design and Research Institute, Beijing, China
}

\begin{abstract}
This paper mainly studies on the mechanical characteristics and application effect of composite metal damper in the high-rise buildings via the numerical simulation analysis. The research adopts the elastic and elastic-plastic dynamic approach and the displacement time history response and damper energy dissipation capacity and so on of the high-rise building are compared and analyzed before and after installation. The analysis found that the energy dissipation characteristic of metallic dampers is good. High-rise building story drift significantly is reduced and the extent of damage of the walls and coupling beams is decreased, achieved a good energy dissipation effect. Composite metal damper can effectively and economically improve the seismic performance of high-rise buildings, meet the requirement of the 3-level design for seismic resistance. The result has certain reference significance for the application of metallic damper in the high-rise buildings.
\end{abstract}

\section{KEYWORDS}

Composite metal damper; Energy dissipation; High-rise buildings; Shear wall structures

\section{INTRODUCTION}

Recently, energy dissipation technology is widely used in engineering. This technology breaks through the limitation of traditional seismic design method, it can effectively improve the structural seismic performance, reduce the seismic response ${ }^{[1]}$.

According to the mechanism of energy dissipation, the commonly used energy dissipation devices are divided into two types: displacement correlation damper, the velocity dependent damper ${ }^{[2]}$. The velocity dependent damper includes viscous damper and viscoelastic damper; The Displacement correlation damper comprises friction damper and Metal damper ${ }^{[3]}$. And the metal damper contains mainly composite metal damper and hysteretic damper. The damping effect is poor under small earthquakes. However, the composite metal damper with superior performance of energy consumption, simple structure, convenient manufacture, low cost, easy replacement ${ }^{[4]}$, is recognized by scholars, engineers and technicians gradually.

Nowadays, high-rise buildings have more motives. The use of shear wall structures accounted for $90 \%$ of high-rise residential ${ }^{[5]}$. Demand for earthquake energy dissipation for high-rise shear is booming. Many scholars have studied the methods to improve the aseismic behavior of shear wall structure. The existing research mainly concentrated in the joints and energy dissipation device and other aspects, such as shear wall with slits ${ }^{[6]}$, combination filling of energy dissipation shear wall ${ }^{[7]}$ and shear wall with vacillated rocking energy swing ${ }^{[8]}$. Compared to the general shear wall structure, those buildings have obvious optimization performance. These methods have some rationality, but the construction to apply them is not convenient.

\section{ENGINEERING APPLICATION}

Composite metal damper used bilinear model in the 
calculation as shown in Figure 1. Bilinear model includes three parameters: second elastic stiffness, stiffness and yield strength.

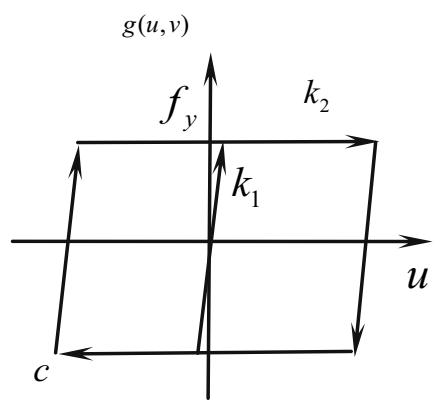

Figure 1. Bilinear hysteretic model of composite metal damper

The project in this paper is a concrete project with damping technology in high rise building. The system of it is frame shear wall, 2 layer underground, 31 floors on the ground, the total height $97.65 \mathrm{~m}$. The seismic intensity is 8 degrees, $0.20 \mathrm{~g}$ design basic acceleration, seismic design group is the first group, the construction site is three categories, the characteristic period of design earthquake response spectrum is 0.42 seconds, Frame and Shear wall seismic grade both Rank as class 1 , the basic wind pressure is $0.45 \mathrm{kN} / \mathrm{m}^{2}$.

For this purpose, use concrete wall as the upper damper support, this can not only increase the support stiffness, but also preserve effect of heat preservation and heat insulation, sound insulation of wall. Damper model was preliminarily selected, after considering the structure characteristics and the construction pattern layout, with optimized design, 100 dampers are arranged, with two each layer along 2 26 layer Along the $\mathrm{X}$ direction and $\mathrm{y}$ direction. The dynamic parameters, Location, Quantity are determined through calculations repeatedly. The basic parameters are shown as follows.

The first stiffness: $1 \mathrm{E} 6 \mathrm{kN} / \mathrm{m}$

The Second stiffness: $0 \mathrm{kN} / \mathrm{m}$

The damper yield force: $30 \mathrm{t}$

Damper rated travel: $4 \mathrm{~cm}$

The maximum stroke damper: $5 \mathrm{~cm}$

The natural period of vibration is an important basis for judgment of rationality of the structure design of high-rise building. Through Comparative test quality, cycle, modal, as table 1 3 show, the finite element shows that the established model is reasonable and accurate.
Table 1. Contrast of the first 3 order periodic (unit: s)

\begin{tabular}{c|c|c|c}
\hline software & first & second & third \\
\hline PKPM & 2.2724 & 1.9789 & 1.5780 \\
\hline SAP2000 & 2.2060 & 2.0426 & 1.5535 \\
\hline PERFORM-3D & 2.194 & 2.021 & 1.501 \\
\hline Vibration direction & $\mathrm{x}-$ & $\mathrm{y}-$ & retortion \\
\hline
\end{tabular}

Table 2. The total mass of structure comparison (unit: $\mathrm{t}$ )

\begin{tabular}{c|c|c|c}
\hline \multirow{3}{*}{$35 \#$} & & mass & deviation \\
\cline { 2 - 4 } & PKPM & 22304.2 & - \\
\cline { 2 - 4 } & SAP2000 & 22983.3 & $3 \%$ \\
\hline
\end{tabular}

Table 3. Comparison of base shear of structures under response spectrum condition(unit:KN)

\begin{tabular}{c|c|c|c|c}
\hline & direction & PKPM & SAP2000 & Deviation \\
\hline \multirow{2}{*}{$35 \#$} & $\mathrm{X}$ & 8011.57 & 8275.82 & $2.1 \%$ \\
\cline { 2 - 5 } & $\mathrm{Y}$ & 9944.05 & 9843.56 & $1 \%$ \\
\hline
\end{tabular}

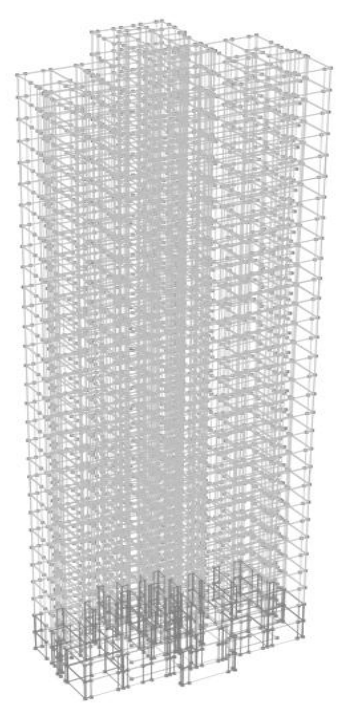

Figure 2. Perspective structure model

According to requirements of "code for seismic design of buildings", during time history analysis, the paper adopts three Seismic waves as follows: site LWD_90 wave, namjyeong-2 wave and one based on artificial wave packet generated seismic site classification. They are shown in fig. 3 to 5 below. 


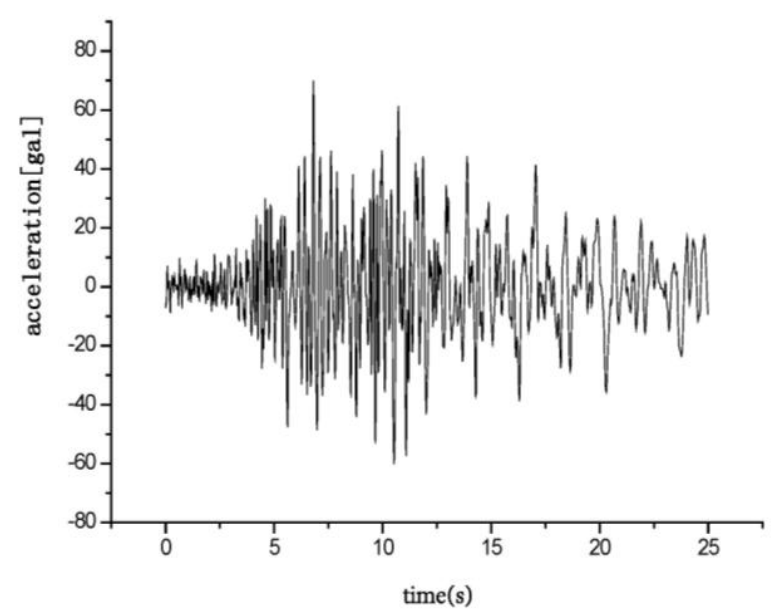

Figure 3. LWD_90 wave

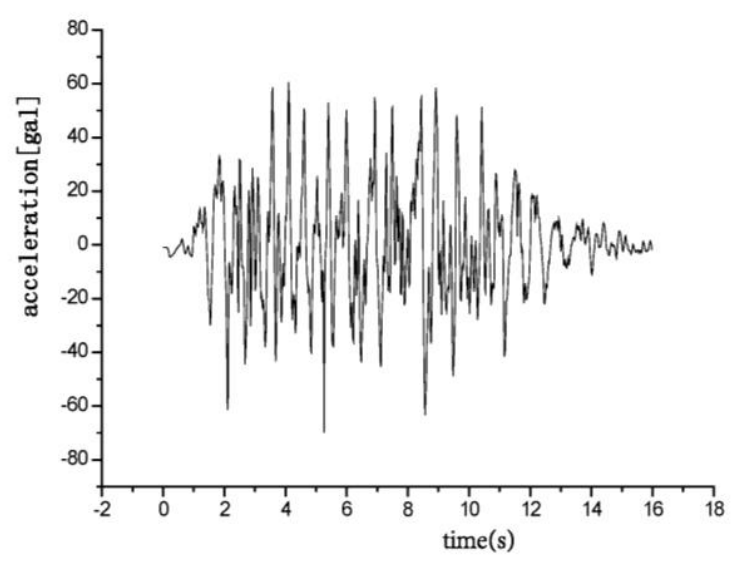

Figure 4. namjyeong-2 wave

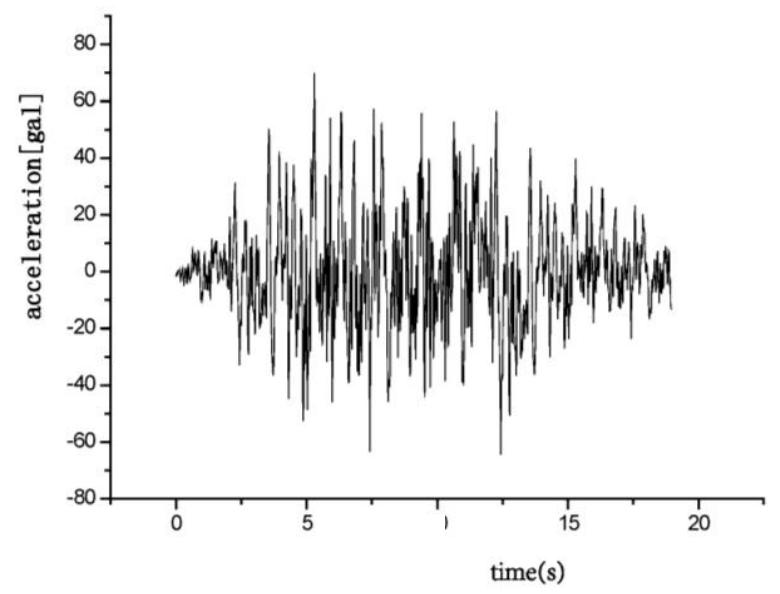

Figure 5. artificial acceleration wave

First, by using SAP2000 to carry on the analysis of seismic response of structure model under 8 degrees of small earthquakes, 8 degrees of moderate earthquakes.

Based on the energy dissipation of dynamic parameters of damper, the layout of the location and quantity of calculations repeatedly, through optimization and adjustment, the parameters changes before and after examining the structure damping and damping effect analysis of damper are researched. Under small earthquake, structure deformation is small. Damper basically don't play its energy consumption, mainly provides additional stiffness.

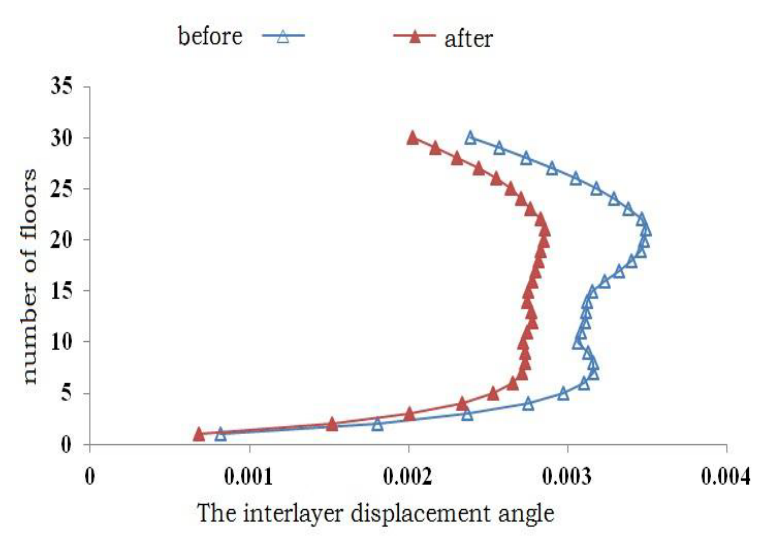

a) X-direction

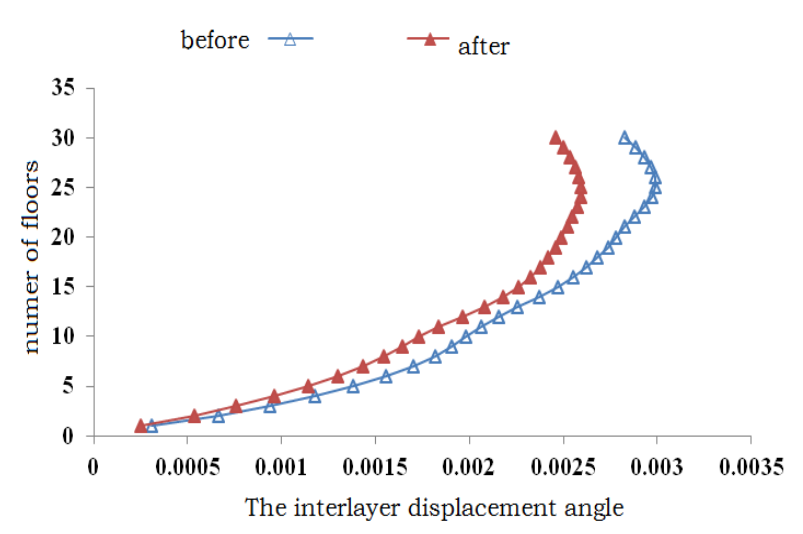

b) Y-direction

Figure 6. The average inter story displacement angle under moderate earthquakes

The Standard requires that elastic limit value of understory drift of reinforced concrete shear wall is 1/1000; elastic-plastic limit value is $1 / 120$. From Figure 6 , under 8 degrees fortification earthquake effect, the interlayer displacement is above the elastic limit, structure is basically in the state of elasticity. After the installation of dampers, overall stiffness of the structure improved a lot, the interlayer displacement angle generally decreased with height. That is to say, the damping effect o is most obvious under moderate earthquakes. Therefore, with the installation of metal 
composite damper, the horizontal deformation of the structure is obviously controlled. From the damper hysteresis curve (Fig.7), in this condition the majority of damper has been yielded to consume the earthquake energy.

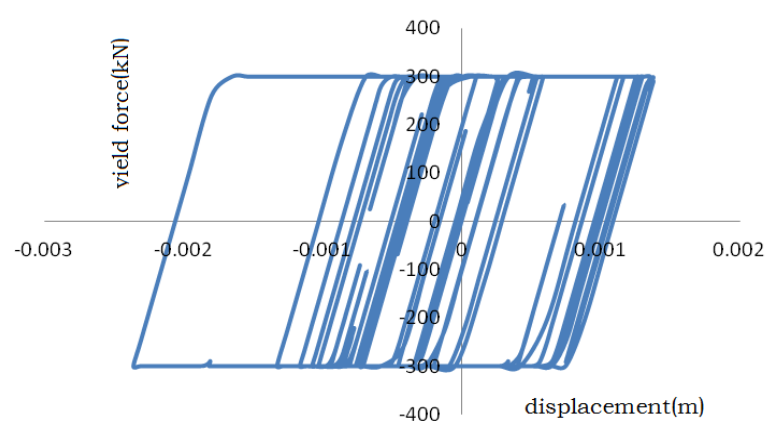

a) X-direction

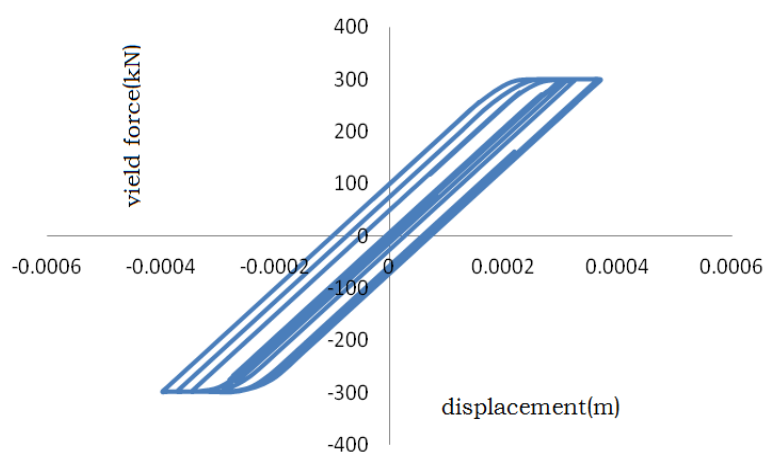

b) Y-direction

Figure 7. Damper hysteresis curve under eight degree earthquake intensity

In this condition of nine degrees fortification earthquake, extract structure layer displacement angle of the most obvious response under artificial wave conditions. (Fig. 8)

With dampers, all the structure interlayer displacement angle decreases. Average damping ratio in $\mathrm{X}$ direction is $5.8 \%$, with the increase of the damping effect of the floor firstly decreased and then increased. While average damping ratio is $11.5 \%$ in $\mathrm{Y}$ direction, with the increase of floor better effect.

The time history of structure under the interlayer displacement angle is showed in figure 9. Under this condition, the maximum inter storey displacement angle of the original model under the artificial wave is $1 / 100$, exceed the specification limits.

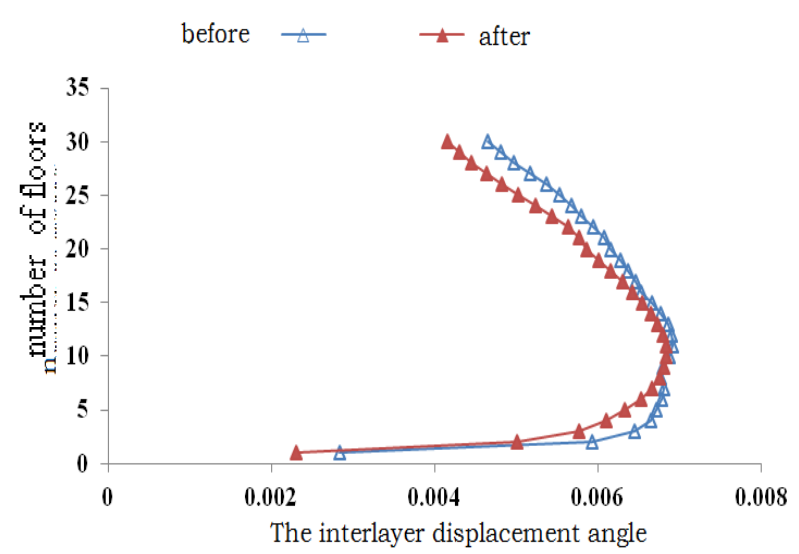

a) X-direction

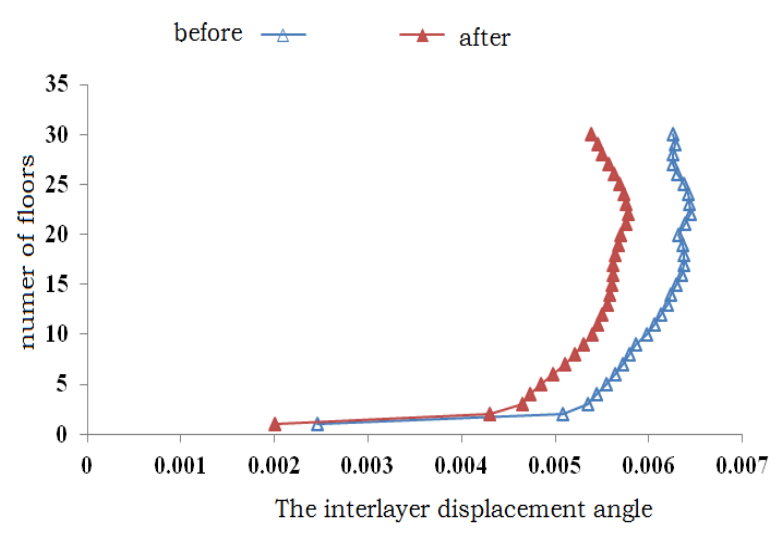

b) Y-direction

Figure 8. Comparison of angle of floor displacement peak value under artificial wave

Time history wave layer displacements are slowed significantly, meet the requirements of code, and with the floor height and better damping effect. The average damping ratio of structure in $\mathrm{X}$ direction is $25.4 \%, \mathrm{Y}$ to $14.6 \%$.

Base shear is a macroeconomic indicator to reflect the total seismic force of structure during an earthquake. From Figure 10 we can see that, The average bottom shear of structures without damper in $\mathrm{x}$ direction is $30998 \mathrm{kN}$, is $34252 \mathrm{kN}$ with damper, reduced by $6.7 \%$. The average bottom shear of structures without damper in $\mathrm{y}$ direction is $42145 \mathrm{kN}$, is $34252 \mathrm{kN}$ with damper, reduced by $18.7 \%$. 


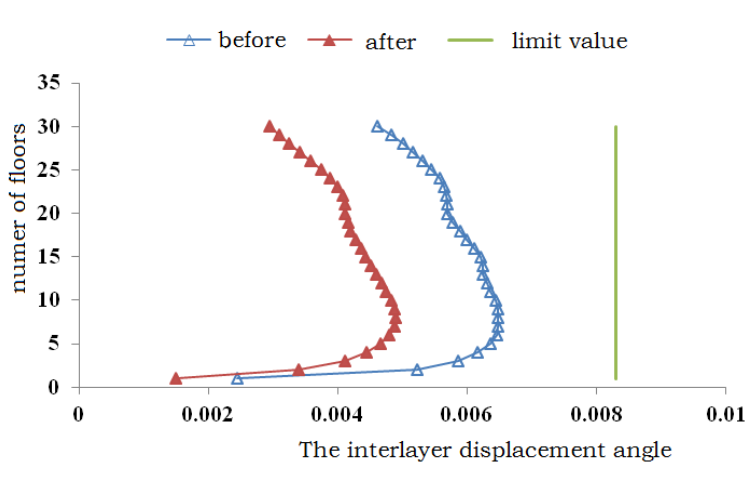

a) X-direction

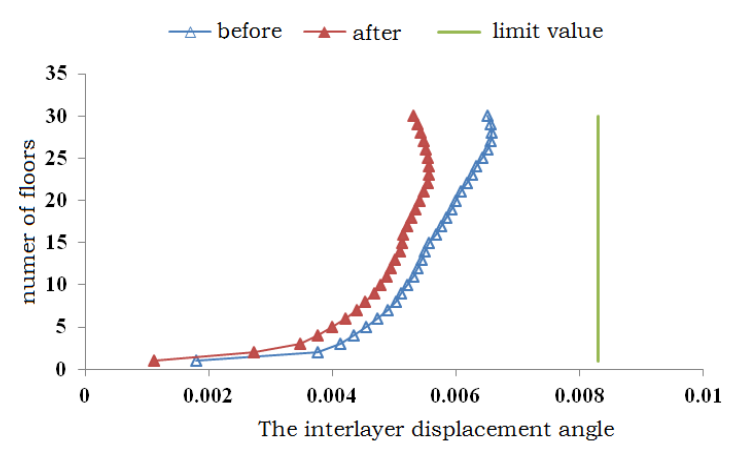

b) Y-direction

Figure 9. Average inter story displacement angle of structure under the three wave of $\mathrm{X}, \mathrm{Y}$ direction

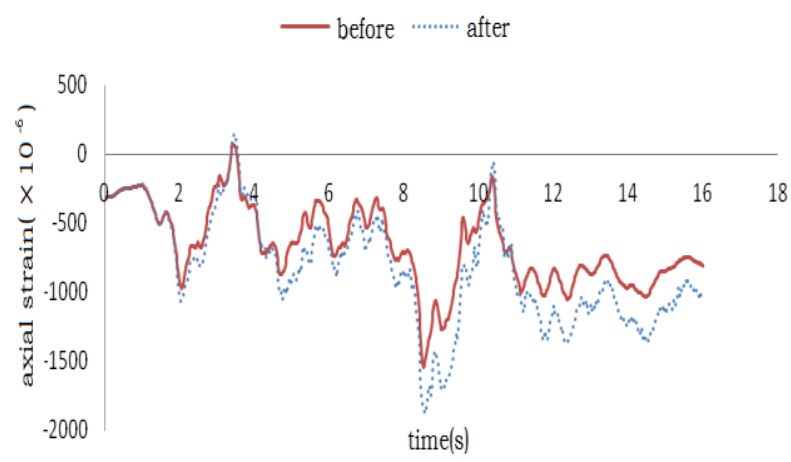

Figure 10. Curves of axial strain of a shear wall

\section{CONCLUSION}

1. Composite metal damper has Plump hysteretic curve and simple structure. Under small earthquakes, it may provide additional stiffness and damping. Under major earthquake, it has stable Energy dissipation, excellent damping effect. Through reasonable arrangement of the damper, The whole structure achieved a good seismic effect.

2. Elastic analysis shows that the main structure basically keep in elastic stage, under 8 degree seismic, most dampers enter the yield stage to consume the earthquake energy.

3. The elasto-plastic analysis shows that, under 9 degree earthquakes, the deformation of main force components is under the control of the LS (the life safety) state. As, the damper played significant damping effect, the structure meet "repairable under moderate earthquake" of the standard fortification requirements.

4.The structure of 9 degrees in the rare case of structure under earthquake response analysis shows that ,Under rare earthquake of 9 degrees, through the response analysis, the structure can achieve the standard 1 lateral requirements, compressive strain of concrete can be controlled under horizontal seismic loads, meet the standard of "earthquake does not fall" fortification requirements.

\section{REFERENCES}

1. Zhou Fulin. Seismic control of engineering structures [M].Beijing: Earthquake Publish Company,(1997)

2. GB50011-2012, Code for seismic design of buildings [S]

3. Soong T T.Dargush G F Passive Energy Dissipation Systems in Structural Engineering,(1997)

4. Analysis to performance of metal damper hysteresis [J]. Industrial Building, 44,49 53(2014)

5. Tan Ping, Zhou Fulin. Research and application of vibration isolation technique $[\mathrm{J}]$. Construction technology, 37,5 8(2008)

6. Ohmori N, Tooyama K, Takeshi T,et al.Studies Reinforced Concrete Slit Walls, 1966.

7. Xia Z M, Naaman A E. Behavior and Modeling of Infill Fiber-reinforced Concrete Damper Element for Steel concrete Shear all [J].ACI Structural Journal, 99,727 739(2002)

8. Ajrab J J, Pekcan G, Mander J B. Rocking Wall-Frame Structures with Supplemental Tendon Systems $[\mathrm{J}]$. Journal of Structural Engineering, 130,895 903(2004) 